\title{
Pluractional Quantifiers: The occasional-construction in English and German ${ }^{*}$
}

\author{
Malte Zimmermann \\ University of Amsterdam / Holland Institute of Generative Linguistics
}

I investigate a syntactic construction which raises an interesting question for compositionality: An adjective seems to be interpreted outside its containing DP, taking scope over the entire sentence. With Larson (1999), I assume that the adjective incorporates into the DP-determiner, forming a complex quantifier. I present independent evidence in favour of such an analysis. Furthermore, I argue that Larson's semantic account of D-A-incorporation is in need of revision. I propose an alternative, more empirically adequate analysis which treats $\mathrm{D}+\mathrm{A}$ composites as Lasersohnian (1995) pluractional quantifiers.

\section{Introduction}

\subsection{The 'Occasional-construction (OC)'}

Bolinger (1967) observes that sentences like (1) are ambiguous. Apart from the expected attributive reading (2b), they also have an 'external' reading, which is synonymous to their adverbial counterpart (2a).

(1) [DP The / An occasional sailor] strolled by.

(2) a. Occasionally, a sailor strolled by. = external (adverbial) reading

b. Someone who sails occasionally strolled by.= attributive reading

On the external reading, the adjective occasional is interpreted like its adverbial counterpart occasionally: It takes wide scope outside the containing DP and modifies the entire sentence. Hence, it is interpreted not in its overt syntactic position, but apparently outside the DP. This creates a mismatch between overt syntactic structure and semantic structure, raising the question how this interpretation is obtained compositionally from syntactic structure.

I will call all those DPs, allowing for external readings of infrequency adjectives contained within them, 'occasional-construction (OC)'. Hence, OCs can occur with any adjective expressing 'infrequency', e.g. sporadic, infrequent, rare, odd. ${ }^{1}$ Examples are given in (3).

(3) a. Sally heard [DP the / a sporadic shot]. 'Sporadically, Sally heard a shot.'

b. [DP The rare bird] was seen. 'Rarely, a bird was seen.'

c. [DP The infrequent visitor] was seen. 'Infrequently, a visitor was seen.' 
In section 1.2, I introduce a number of syntactic and semantic restrictions on OCs. In section 2, I argue that Larson's (1999) syntactic analysis of OCs, which assumes complex quantifier formation by incorporating an adjective into a determiner, is correct, and that it accounts (i) for the mismatch problem, and (ii) for the restrictions on OCs. In section 3, I present new evidence from German in favour of the complex quantifier analysis. In section 4, I argue that the semantic part of Larson's analysis must be revised since it makes a number of incorrect predictions. I propose an empirically more adequate semantics of OCs as pluractionality markers in the sense of Lasersohn (1995), which also sheds some light on the restriction of OCs to infrequency adjectives.

\subsection{Restrictions on OCs}

Stump (1981) and Larson (1999) observe that OCs obey the following syntactic and semantic constraints.

First, the infrequency adjective must be adjacent to the determiner (Stump 1981, Larson 1999). Intervening adjectives block the external reading (cf. 4b).

a. [The / An occasional well-dressed sailor] strolled by. 'Occasionally, a well-dressed sailor strolled by.'

b. [The / $A$ well-dressed occasional sailor] strolled by. NOT: 'Occasionally, a well-dressed sailor strolled by.

Second, the infrequency adjective must not be coordinated with another adjective (Stump 1981).

(5) [The / An occasional and well-dressed sailor] strolled by.

NOT: 'Occasionally, a well-dressed sailor strolled by.'

Third, the DP must be headed by a definite or indefinite (singular) article (6a), or by the 2 sg. possessive pronoun. (6b). OCs are impossible with cardinal quantifiers (7a), strong quantifiers (7b), or demonstratives (7c) (Larson 1999).

(6) a. [The/ An occasional customer] entered the shop.

'Occasionally, a customer entered the shop.'

b. Well, [your occasional sailor] would also show up.

'Occasionally, a sailor would show up.'

(7) a. [Two occasional customers] entered the shop.

NOT: 'Occasionally, two customers entered the shop.'

b. [Every occasional customer] entered the shop.

NOT: 'Occasionally, every customer entered the shop.'

c. [This occasional customer] entered the shop.

NOT: 'Occasionally, this customer entered the shop.' 
Fourth and last, OCs only occur with infrequency adjectives (Larson 1999). Frequency adjectives are out despite their having adverbial counterparts. ${ }^{2}$
a. [A frequent sailor] strolled by.
NOT: 'Frequently, a sailor strolled by.'
b. Barbara saw [a regular customer].
NOT: 'Regularly, Barbara saw a customer.'

Obviously, any analysis of OCs should contain an adequate account of these restrictions, apart from solving the mismatch.

\section{Solving the mismatch}

\subsection{The problem}

The existence of external readings for infrequency adjectives constitutes a problem for compositionality. Let us look at (9) for illustration.

The occasional sailor strolled by.

Since the external reading of (9) is synonymous to that of its adverbial counterpart (cf. 2a), its semantic structure should be structurally similar to that of the latter. Thus, the overt syntactic structure in (10) will translate as (11a), if we adopt an unselective binding approach to adverbial quantification (e.g. Lewis 1975, Kamp 1981, Heim 1982), or as (11b), if we assume that temporal adverbials quantifiy over an implicit event/situation-argument (e.g. Heim 1990, De Swart 1991, Von Fintel 1994).

(10) [IP [DP The [NP occasional [NP sailor]]] [vP e(vent) [strolled by]]].

(11) a. OCCASIONAL $<\mathrm{e}, \mathrm{x}>$ [sailor(x) \& event (e)] (strolled-by (x,e)) ${ }^{3}$ 'There is an occasional pair of event $\mathrm{e}$ and sailor $\mathrm{x}$ : $\mathrm{x}$ strolls by at $\mathrm{e}$.'

b. OCCASIONAL $<\mathrm{e}>$ [event $(\mathrm{e})](\exists \mathrm{x}$ (sailor $(\mathrm{x}) \&$ strolled-by $(\mathrm{x}, \mathrm{e}))$ 'There is an occasional event $\mathrm{e}$ : there is a sailor strolling by at e.'

Both semantic structures in (11) share the relevant structural property: The temporal quantifier OCCASIONAL has scope over the entire sentence. ${ }^{4}$ In particular it semantically binds a Davidsonian (1967) event variable, which is syntactically located in the outermost argument position of VP in (10) (cf. Kratzer 1995). Now, the adjective occasional in (10) cannot syntactically bind the event variable from its overt DP-internal position because it does not c-command it. Since semantic binding is contingent on syntactic binding (cf. Heim \& Kratzer 1998), we must conclude that the adjective occasional does not semantically bind (and quantifiy over) the event variable in (10). Hence, we cannot derive the external reading from the syntactic structure in (10), let alone compositionally. 
$A$ priori, there are three options to get the adjective in (10) into a position from where it can bind the event argument: (i) LF-extraction of the adjective as in (12a); (ii) LF-movement of the adjective to the specifier position of DP in a Kaynean (1994) fashion as in (12b); (iii) the formation of a complex quantifier by incorporating the adjective into the determiner as in (12c).

a. [IP occasional 1 [IP [DP the / a t $\mathrm{t}_{1}$ sailor] [VP e strolled by]]].

b. [IP [DP occasional ${ }_{1}$ [ the / a t $t_{1}$ sailor] ] [vP e strolled by]]. ${ }^{5}$

c. $\left[\mathrm{IP}\left[\mathrm{QP}\left[\mathrm{Q}\right.\right.\right.$ the/an+occasional $\left.{ }_{1}\right]\left[\mathrm{NP}_{\mathrm{1}} \mathrm{t}_{1}\right.$ sailor $\left.]\right]$ [vP e strolled by]].

These three options correspond to Mattewson's (1998) threefold distinction of quantificational structures into A-, DP-, and D-quantification. They differ as to the position and nature of the quantificational element. It can be an adverbial (with A-quantification), a modifier in SpecDP (DP-quantification) ${ }^{6}$, or a quantificational head in D (D-quantification).

I follow Larson (1999) and Stump (1981) and assume that the adjective syntactically incorporates into the determiner, forming a complex syntactic element (cf. 12c). In 2.2, I discuss some conceptual and empirical problems for the alternative derivations (12a,b). In 2.3 and 2.4 , I present Larson's analysis and show how it accounts for (most of) the restrictions on OCs.

\subsection{Arguments against $L F$-extraction or $L F$-movement to SpecDP}

The following arguments against LF-moving the adjective out of or to the Spec of DP are not meant to be conclusive. They only serve to illustrate that solution (12c) faces fewer problems than the alternatives in (12a,b).

An LF-extraction-account faces both conceptual and empirical problems. First, the extracted adjective in (12a) has an interpretive (binding) relation with the event variable inside VP, but not with its own trace. This is not like 'ordinary' $\mathrm{QR}$, where the raised QP must bind its trace in order to ensure proper thematic interpretation. Thus, (12a) forces us to assume that adjective-extraction is different from 'ordinary' QR. Besides, if there is no semantic relation between the extracted adjective and its base position, the question arises as to why the adjective is generated inside DP at all (cf. Larson 1999).

Empirically, the LF-extraction account faces two problems. First, Larson (1999) observes that an infrequency adjective inside a definite DP corresponds to an infrequency adverbial outside an indefinite DP (13a,b).

(13) a. [DPdef The occasional customer] entered the shop.

b. Occasionally, [DPindef a customer] entered the shop.

If occasional in (13a) raised out of DP (presumably yielding an LF-structure isomorphic to the overt structure (13b), modulo the choice of determiner), we 
would expect (14) to be synonymous to (13a). This is not the case, leaving us with no explanation for the difference in reading between the two sentences.

Occasionally,[DPdef the customer] entered the shop.

Second, definite NPs are usually thought to be opaque for overt and covert extraction (cf. Fiengo \& Higginbotham 1981). This is illustrated in $(15 \mathrm{a}, \mathrm{b})$ for overt wh-extraction and covert $\mathrm{QR}$.
a. *Who did you see [the picture of $\mathrm{t}$ ]?
b. ?[This man from every American city] owns a Porsche.
NOT:'For every A.n city there is this man $\mathrm{x}, \mathrm{x}$ owns a Porsche.'

As a consequence, extraction of the adjective in (13a) should be blocked by the opacity of the containing definite DP.

This last argument does not carry over to the Movement-to-SpecDP account (12b) because here the adjective is not extracted out of DP. However, this approach offers no principled explanation of the data in (13a,b) and (14) either. In addition, it does not explain the fact that external readings are possible with infrequency adjectives, but not with frequency adjectives.

In sum, we have seen that there are reasons to be sceptical about the first two approaches in (12). Let us turn to the third alternative (cf. 12c) instead.

\subsection{Complex Quantifier Formation (CQF) (Larson 1999)}

Larson (1999) analyzes OCs as involving the formation of a complex quantifier by incorporation of the adjective into the determiner. His syntactic structure for (1) is given in (16) $(=12 c)$, his semantic structure in (17).

[IP [QP $\left[Q\right.$ the/an+occasional $\left.{ }_{1}\right]$ [NP $\mathrm{t}_{1}$ sailor]] [vP e strolled by]].

INFREQ $<\mathrm{e}, \mathrm{x}>$ [part-of $\left(\mathrm{e}, \mathrm{e}^{*}\right) \&$ sailor(x)] (strolled-by $\left.(\mathrm{x}, \mathrm{e})\right)$

'For few pairs $<\mathrm{e}, \mathrm{x}>$ such that $\mathrm{e}$ is part of some larger contextually given event $\mathrm{e}^{*}$, and $\mathrm{x}$ is a sailor, e consists of a strolling by of $\mathrm{x}$.'

In other words, the adjective in an OC is not a quantificational element by itself. It forms a syntactically complex element with the determiner by head-adjunction to the latter. ${ }^{7}$ The resulting complex element translates as the quantifier INFREQ, which quantifies over pairs of events and individuals. This analysis ensures isomorphy between syntactic and semantic structure, involving only minimal syntactic movement. The semantic value can be computed from LF compositionally, using standard PTQ-semantics (e.g. Montague 1973): the complex quantifier is a function that forms a Generalized Quantifier with the denotation of its NP-complement. This GQ takes the VP-denotation as its semantic argument, mapping it onto a truth-value. 
The CQF-analysis does not face the problems encountered by the alternative analyses. The complex quantifier [Q $\mathrm{D}+\mathrm{A}]$ can bind the event variable from its overt position inside DP. LF-extraction via QR does not apply, hence the problem regarding extraction out of definite DPs vanishes. The difference in meaning between (13a) and (14) is explained by the fact that these sentences have different LF-structures. (13a) contains no independent determiner the at LF, only a complex quantifier formed by the +occasional.

\subsection{CQF accounts for the restrictions on OCs}

Larson's CQF-analysis accounts for three of the four restrictions on OCs.

Since $\mathrm{CQF}$ is the result of syntactic head-movement, the adjacency requirement and the non-coordination requirement (illustrated again in 18a,b) are accounted for on the base of general restrictions on (head) movement.

a. [The / A [well-dressed [occasional sailor]]].

b. [The / An [[occasional and well-dressed] sailor]].

(18a) has no external reading because incorporation of the adjectival head occasional into the determiner across the intervening head well-dressed is excluded by the 'Head Movement Constraint (HMC)' or any of its Relativized Minimality or Minimalist successors (cf. Travis 1984, Rizzi 1990, Chomsky 1995). In (18b), head movement of occasional to D is blocked by the 'Coordinate Structure Constraint (CSC)' (Ross 1967).

The restriction that OCs must be headed by a definite or indefinite article is explained if we assume that CQF is possible only with non-quantificational and kind-denoting elements. This generalization blocks intrinsically quantificational elements and intrinsically deictic elements from undergoing complex quantifier formation (cf. 19a,b): ${ }^{8}$

a. Two / many / most/ every occasional sailor(s) strolled by.

b. This occasional sailor strolled by.

Only definite and indefinite article (and the 2sg. possessive pronoun) are kinddenoting and non-quantificational at the same time. Their non-quantificational character is discussed in Heim (1982). Their ability to denote types is witnessed by the fact that they can be used in generic statements.

(20) a. The / A whale is a mammal.

b. Your average whale is $6 \mathrm{~m}$ long.

This leaves us with the last restriction. So far, the analysis cannot explain why frequency adjectives like frequent are excluded from OCs. In section 4.4, I will argue that the reason for this is essentially the same as the one that bans 
quantificational and deictic determiners from this construction. The semantic nature of frequency adjectives is not compatible with that of complex quantifiers in OCs. Hence, they cannot undergo CQF, and no OC is formed.

\section{The QP-status of OCs: Independent evidence from German}

\subsection{Complex Quantifier Formation in German}

There is disagreement in the literature on the categorial status of the complex element [D+A]. Stump (1981) takes it to be a frequency operator on propositions, while Larson (1999) treats it as a complex quantifier (turning the entire OC into a QP). In this section, I support the quantificational view with independent evidence from German, which also has OCs. First, I show that German has other [D+A]compounds with a quantifier meaning. Second, I argue in 3.2 that a QP-analysis of OCs explains an interesting divergence between English and German OCs.

Let us first look at independently attested cases of CQF. Haspelmath (1995:366) observes that the sequence of definite article die 'the' and the adjective ganzen 'whole, entire, intact' is often interpreted as a universal quantifier in contemporary spoken German. In (21a), this is the only reading available. In (21b), the quantifier reading is strongly preferred over the 'normal' attributive reading (Haspelmath's exs. 6a,b).
a. Wer hat
denn die ganzen Punkte hier gemalt?
Who has then the wholedots here painted
'Who has painted all the dots here?' (Q-reading)
NOT: 'Who has painted the whole/entire dots here?' (attr. Reading)
b. Die ganzen Tassen sind verschwunden.
The whole cups have disappeared
'All the cups have disappeared.' (Q-reading)
'The intact cups have disappeared.' (attr. Reading)

The universally quantified reading of structures $(21 a, b)$ is easily accounted for if we assume a syntactic structure like (22a), which is isomorphic to the proposed structure for OCs (repeated here as 22b).
a. [IP [QP [Q die $\operatorname{det}+$ ganzen $\left._{a d j, 1}\right]$ [NP $t_{1}$ Tassen] [VP sind verschwunden]].
b. [IP [QP[Q the/an+occasional $\left.{ }_{1}\right]$ [NP $\mathrm{t}_{1}$ sailor]] [vp e strolled by]].

Furthermore, complex universal quantifier formation from articles (overt or covert) and adjectives expressing 'wholeness' is attested diachronically in a variety of languages from different language families (cf. Haspelmath 1995).

I conclude that $\mathrm{CQF}$ with OCs is not an exotic accident, but an instance of a process of grammaticalization, which is attested cross-linguistically: articles and adjectives can combine to form a complex quantifier. ${ }^{9}$ The meaning of the newly formed quantifier depends non-arbitrarily on the original meaning of the 
adjective. If the adjective expresses 'wholeness', the complex quantifier will be universal (cf. Haspelmath 1995:366f.). If it expresses infrequency (in OCs), the quantifier will be pluractional. I discuss pluractionality in section 4 .

\subsection{The different distribution of OCs in English and German}

Analyzing OCs as Quantifier Phrases (QPs) also enables us to account for an interesting divergence in the distribution of OCs in English and German.

In English, OCs can occur in subject (23a), direct object (23b), indirect object (23c), and prepositional object/locative position (23d).
a. [An occasional customer] entered the shop.
'Occasionally, a customer entered the shop.'
b. PAGAD blows up [the occasional building].
'Occasionally, PAGAD is blowing up a building.'
c. Bill sent [an occasional woman] flowers.
'Occasionally, Bill sent a woman flowers.'
d. We stopped at [the occasional roadhouse].
'Occasionally, we stopped at a roadhouse.'

In German, OCs are restricted to subject position (cf. 24a-d).
a. [ Ein gelegentlicher
Kunde] betrat den Laden.
(SUBJ)
an occasional
customer entered the shop

'Occasionally, a customer entered the shop.'
b. * PAGAD zerstörte [das gelegentliche Gebäude].
PAGAD destroyed the occasional building
c. * Peter schickte [einer gelegentlichen Frau] Blumen. (IO)
Peter sent an occasional woman flowers

d. * Wir stoppten bei [dem gelegentlichen Rasthaus].

We stopped at the occasional roadhouse

We can attribute this difference in distribution to the fact that in German - unlike in English - nonsubject-QPs never receive sentence-level scope. This is generally attributed to the absence of QR to sentence-initial position in German (cf. Saeboe 1995, Krifka 1998), as witnessed by the inavailability of inverse scope readings for (25a,b) under neutral intonation (cf. Frey 1993, Pafel 1993, Krifka 1998).

a. Ein Mann liebt jede Frau. a/some man loves every woman NOT: 'For every woman $y$, there is some man $\mathrm{x}$, such that $\mathrm{x}$ loves $\mathrm{y}$.'

b. Ein Verehrer schickte jeder Frau Blumen. a/some admirer sent everywoman flowers NOT:'For every woman $y$, there is an admirer $\mathrm{x}$, who sent $\mathrm{y}$ flowers.' 
Now, given that an OC requires sentential scope at LF for interpretability (only then can it bind the event-variable in the outermost VP-position), we predict OCs to be blocked from German VP-internal positions because they cannot receive appropriate scope (due to the inapplicability of $Q R$ ). Hence, treating OCs as QPs allows for a unified explanation for the absence of non-subject OCs and the absence of inverse scope readings in German. ${ }^{10,11}$

The QP-analysis of OCs makes another interesting prediction. OCs should be possible with non-subjects in German, if the latter have raised out of VP overtly. In this case, they can bind the event variable and receive a proper interpretation. This prediction seems to be borne out, as illustrated in (26).

$$
\begin{gathered}
{\left[\mathrm{CP}[\text { Das gelegentliche Bierchen }]_{1}\right. \text { trinken }} \\
\text { the occasional beer-ACC drink }
\end{gathered}
$$

'Of course, we occasionally drink a beer, too.'

To conclude, we have seen (i) that there are independent instances of complex quantifiers formed from article and adjective in German, thus motivating the CQF-analysis for OCs; (ii) that a quantifier analysis of the complex [D+A] (resulting in a QP-analysis for OCs) helps to explain the different distribution of OCs in English and German .

\subsection{Weak vs. Strong}

Regarding the status of OCs as weak or strong QPs, I argue that OCs constitute weak (i.e. intersective) QPs. This claim is supported by empirical evidence as well as by theoretical considerations.

OCs are able to occur in existential there-sentences. This is a standard diagnostic for weak QPs (cf. Milsark 1977, de Hoop 1995).

a. There was an occasional sailor strolling by.

b. There were some/ two/ more than five sailors strolling by. (weak QPs)

c. *There were all/ most sailors strolling by. (strong QP)

In addition, treating of OCs as strong QPs yields the wrong truthconditions for sentences like (28), with the semantic structure (29).

(28) We watched an occasional ship.

(29) INFREQ<e, $x>$ [part-of(e,e*) \& $\left.\operatorname{ship}^{\prime}(\mathrm{x})\right]$ (watch'(we, $\left.\mathrm{x}, \mathrm{e}\right)$ )

$=$ 'Few of all event-ship pairs are such that we watch $\mathrm{x}$ at $\mathrm{e}$.'

If the complex quantifier, translated as INFREQ, was strong, (29) would correctly predict (28) to be true in a situation with a relatively large number of ships of which we watched only few (because we were not paying much attention to the ships). However, (28) is also true in a situation with only few ships to begin 
with, but in which we watched all of these few ships. This situation is not covered by the semantics in (29) on a strong quantifier analysis. (29) would predict (28) to be false in such a situation, contrary to fact. ${ }^{12}$

If we treat OCs as weak QPs, this problem does not arise. The semantic representation in (30) predicts (28) to be true in both situations, while being maximally isomorphous to its syntactic structure.

$$
\begin{aligned}
& \text { INFREQ } \left.<e, x>\left[\text { part-of }\left(e, e^{*}\right) \& \text { ship' }(x)\right](\text { watch'(we, } x, e)\right) \\
& =\text { 'There are few event-ship pairs }<e, x>\text { such that we watch } x \text { at e.' }
\end{aligned}
$$

Given the additional empirical evidence in (27a), I conclude that OCs are QPs headed by the weak quantifier INFREQ, realized as the complex [D+A].

\section{The occasional-construction as a pluractionality marker}

\subsection{Two incorrect predictions of Larson (1999)}

In this section, the semantics of OCs are subject to further scrutiny. I show that Larson's semantic analysis of OCs is in need of revision because it makes some incorrect predictions regarding the truth conditions of OCs, even if we treat them as weak QPs. In 4.2 and 4.3, I introduce Lasersohn's (1995) notion of 'pluractionality marker' and apply it to OCs. I show that an analysis of OCs as 'pluractional quantifiers' is empirically more adequate than Larson's (1999) analysis. Finally, I discuss how an analysis using pluractionality marking accounts for the restriction of OCs to infrequency adjectives.

Let us look at the Larsonian semantics for (16) (repeated as 31a,b) again:

a. [IP [QP $\left[\mathrm{Q}\right.$ The/an+occasional 1 ] [NP $\mathrm{t}_{1}$ sailor]] [vP e strolled by]].

b. INFREQ $<\mathrm{e}, \mathrm{x}>$ [part-of(e,e*) \& sailor(x)] (strolled-by $(\mathrm{x}, \mathrm{e})$ )

'There are few event-sailor pairs $<e, x>$ such that e consists of a strolling by of $\mathrm{x}$.'

(31b) incorrectly predicts (31a) to be true in the following two situations:

(32) a. Situation A: The same sailor $x 1$ strolled by three times in an hour, and nobody else strolled by in that hour $(<\mathrm{e} 1, \mathrm{x} 1>,<\mathrm{e} 2, \mathrm{x} 1>,<\mathrm{e} 3, \mathrm{x} 1>)$.

b. Situation B: For an hour, nobody strolled by except for three sailors who walk past at the same time $(<\mathrm{e} 1, \mathrm{x} 1>,<\mathrm{e} 1, \mathrm{x} 2>,<\mathrm{e} 1, \mathrm{x} 3>)$.

In both situations, there are few sailor-event pairs $<e, x>$ that satisfy the conditions in (31b). Still, (31a) cannot be used to describe these situations. ${ }^{13}$ (33) is a more adequate rendering of the truth-conditions of (31a). 
(33) There are some pairs $<$ e, $x>$ of event e (part of a larger contextually given event $\mathrm{e}^{*}$ ) and sailor $\mathrm{x}$, such that e consists of a strolling by of $\mathrm{x}$, AND (i) no sailor $x$ participates in a strolling-by event e more than once, AND (ii) no two strolling-by events of sailors overlap in time.

The addition of (33i) blocks (31a) from being true in situation $\mathrm{A}$, the addition of (33ii) blocks it from being true in situation $\mathrm{B}$. The additional semantic properties of OCs expressed by the italicized clauses $(33 \mathrm{i}, \mathrm{ii})$ are characteristic properties of 'pluractionality markers' as discussed in Lasersohn (1995), a fact which strongly argues for an analysis of OCs in terms of pluractionality.

\subsection{Pluractionality markers}

Pluractionality markers are elements that modify event-denoting expressions (Vs or VPs) and yield a plurality of events. Lasersohn (1995) considers them to function similarly to plural markers in the nominal domain, which modify individual-denoting, singular NPs and yield pluralities of individuals.

According to Lasersohn (1995) there are three ways in which an event can pluralized. A pluralized event can be temporally iterated (cf. 34a), spatially scattered (cf. 34b), or it can consist of individually performed actions (as opposed to collective actions) (cf. 34c).

(34) a. He whistled again and again / every now and then / time and again.

b. It rained here and there.

c. The students came in individually / one at a time.

Pluractionality markers, then, induce (i) distribution of events over points in time, and/or (ii) distribution over points in space, and/or (iii) distribution of events over individuals.

Languages differ as to how they mark pluractionality syntactically. Some languages (North American, Dravidian, West African languages) feature a pluractional suffix which attaches to the verb. In English, pluractionality is expressed by VP-modifiers, often syntactically complex adverbials (cf. 34a-c), or by distributive quantifiers like each or every (cf. 35).

$$
\text { [IP [QP [Q Each] man] [vP lifted the table]]. }
$$

In (35), the presence of the quantifier each (instead of e.g. all, which allows for, or even favours a collective construal) leads to the construal of a plurality of events of table-liftings which are distributed over different men. 


\subsection{OCs as pluractionality markers}

The close relation between the semantics of OCs (cf. 33) and that of other pluractionality markers like those in 4.2 is obvious. I take the complex head $[\mathrm{D}+\mathrm{A}]$ in OCs to have two semantic functions. Apart from quantifying over pairs of events and individuals, it also functions as a pluractionality marker. It causes distribution of events over individuals (no individual may participate in more than one event (cf. 33i), AND over time (no two events may overlap in time (cf. 33ii).

My analysis differs from Stump's (1981) in that I do not assume that the pluractional nature of the complex $[\mathrm{D}+\mathrm{A}]$ automatically blocks it from being a quantifier. Instead, I treat it analogously to the distributive universal quantifiers each and every. Just like those need a lexical specification that sets them apart from their non-distributive counterpart all, I take the quantifier [D+A] to carry an additional semantic marking for pluractionality.

Given that the distributive quantifiers each and every are able to modify the event structure from their syntactic position, resulting semantically in a plurality of events, it should come as no surprise that the same is possible with the pluractional quantifier $[\mathrm{D}+\mathrm{A}]$ in OCs. The structural isomorphy between these two kinds of pluractional quantifiers is illustrated in (36). ${ }^{14}$

(36) a. [IP [QP [Q The/an+occasional 1 ] [NP $\mathrm{t}_{1}$ sailor]] [VP e strolled by]].

b. [IP [QP [Q Each] man] [vP lifted the table]].

Lasersohn (1995:251-253) formalizes the effects of event-distribution over points in time in the following way:

(37) Distribution over points in time:

VPpluractional $(\mathrm{X}) \Leftrightarrow \forall \mathrm{e}, \mathrm{e}^{\prime} \in \mathrm{X}\left[\mathrm{VP}(\mathrm{e}) \& \neg\left(\tau(e)\right.\right.$ o $\left.\left.\tau\left(e^{\prime}\right)\right)\right] \&|\mathrm{X}|>2$. (with $\tau=$ time of occurrence, $o=$ overlap-relation)

(37) reads as 'The value of a pluractionally modified VP applied to a set of events $\mathrm{X}$ is equivalent to: for any two events e, e' which are elements of a set $\mathrm{X},|\mathrm{X}|>2$, the events fulfill the unmodified VP-predicate, and the two events do not overlap in time'.

Using (37), we can formulate the lexical entry for the pluractional quantifier INFREQ, illustrated by our standard example [the occasional]:

a. $\quad[$ the occasional $] \Rightarrow[\mathrm{INFREQ}<\mathrm{e}, \mathrm{x}>]$

b. $\quad[$ INFREQ $<e, x>]=\lambda Q \lambda S$. there are some pairs $<e, x>$, with e part of a (contextually given) event $\mathrm{e}^{*} \& \mathrm{Q}(\mathrm{x})$, such that $\mathrm{S}(\mathrm{e}, \mathrm{x}) \& \forall<\mathrm{e}^{\prime}, \mathrm{x}^{\prime}>$, $<\mathrm{e}^{\prime \prime}, \mathrm{x}^{\prime \prime}>$ such that $\left[\mathrm{S}\left(\mathrm{e}^{\prime}, \mathrm{x}^{\prime}\right) \& \mathrm{~S}\left(\mathrm{e}^{\prime \prime}, \mathrm{x}^{\prime \prime}\right) \& \mathrm{Q}\left(\mathrm{x}^{\prime}\right) \& \mathrm{Q}\left(\mathrm{x}^{\prime}{ }^{\prime}\right)\right] \Rightarrow\left[\mathrm{x}^{\prime}=\mathrm{x}\right.$ '” $\left.\& \mathrm{e}^{\prime}=\mathrm{e}^{\prime \prime}\right] \vee\left[\mathrm{x}^{\prime} \neq \mathrm{x}\right.$ ' \& $\mathrm{e}^{\prime} \neq \mathrm{e}^{\prime \prime} \& \neg\left(\tau\left(\mathrm{e}^{\prime}\right)\right.$ o $\left.\left.\tau\left(\mathrm{e}^{\prime \prime}\right)\right)\right]$.

By $\lambda$-conversion with $Q=(\lambda x$.sailor' $(x))$ and $S=(\lambda$ e $\lambda x$.stroll-by'(x,e) $)$, we get: 
(39) a. There are some pairs $<e, x>$, with e part of a (contextually given) event $\mathrm{e}^{*}$, and sailor'(x), such that stroll_by'(e,x), and for $\forall<\mathrm{e}^{\prime}, \mathrm{x}>,<\mathrm{e}^{\prime \prime}, \mathrm{x}^{\prime}>$

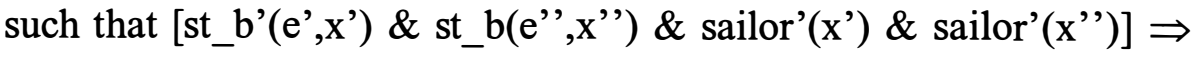
$\left[\mathrm{x}^{\prime}=\mathrm{x}{ }^{\prime}, \& \mathrm{e}^{\prime}=\mathrm{e}^{\prime \prime}\right] \vee\left[\mathrm{x}^{\prime} \neq \mathrm{x}{ }^{\prime}, \& \mathrm{e}^{\prime} \neq \mathrm{e}^{\prime \prime} \& \neg\left(\tau\left(\mathrm{e}^{\prime}\right)\right.\right.$ o $\left.\left.\tau\left(\mathrm{e}^{\prime \prime}\right)\right)\right]$

b. There are some pairs $\langle e, x\rangle$, with e part of a (contextually given) event $\mathrm{e}^{*}$, and $\mathrm{x}$ a ailor, such that $\mathrm{e}$ is a strolling-by of $\mathrm{x}$, and any two strolling-by events are performed by different sailors and occur at separate points in time.

The truth-conditions in (39b) are identical to the informal rendering in (33).

\subsection{The restriction to infrequency adjectives explained}

Let us finally turn to the question why OCs only occur with infrequency adjectives. We have seen that the complex quantifier [D+A] in OCs has the syntactic and semantic properties of a pluractionality marker. Syntactically, pluractionality markers are often complex (cf. 34a-c), i.e. they can be formed productively in the syntactic component. Semantically, they have a non-overlap condition built in. In the case of OCs, this non-overlap condition enforces distribution of the event in question over separate individuals and over separate points in time.

I would like to argue that these two properties taken together block frequency adjectives from occurring in OCs. The pluractional semantics of OCs do not license frequency expressions because these - unlike infrequency expressions - do not guarantee non-overlap of events, as illustrated in $(40 \mathrm{a}, \mathrm{b})$.

(40) a. In those days, we occasionally built houses. (non-overlap)

$\rightarrow$ periods of house-building alternate with periods of non-house-building.

b. In those days, we frequently built houses.(overlap)

$\rightarrow$ no particular periods of non-house-building discernible.

Thus the absence of frequency adjectives from OCs is accounted for. The semantic non-overlap requirement of OCs as pluractional expressions clashes with the inherent semantic properties of frequency expressions, which do not license the construal of non-overlapping events.

On the syntactic side, frequency adjectives seem unable to combine with articles in order to form their own class of 'frequency constructions', at least not in English or German. The grammars of these languages (and perhaps generally) do not seem to allow for the formation of frequency expressions in the syntactic component, thus blocking the formation of frequency constructions. 


\section{Conclusion}

In this paper, I have argued that OCs are formed by complex quantifier formation (CQF) through incorporation of an adjective into a determiner. Citing evidence from German I have argued that $\mathrm{CQF}$ is independently attested elsewhere, and that a complex quantifier analysis accounts for the divergence in syntactic distribution of OCs in English and German. Lastly, I have argued that OCs are pluractionality markers in the sense of Lasersohn (1995). This explains why OCs cannot be formed with frequency adjectives.

\section{Endnotes}

* I would like to thank Richard Larson for drawing my attention to the problem of OCs, for reading a previous version of this paper, commenting on it, and for his encouragement to go public with it. I also thank the audiences at the 000-talk in Leiden in November 99, at Console 8 in Vienna in December 1999, and at SALT $\mathrm{X}$ at Cornell University, Ithaca, for their stimulating discussion and fruitful comments. All errors and omissions are of course my own.

1. The term 'infrequency' does not refer to the absolute number of occurrences of a particular event. An event can be infrequent even though the absolute number of its instantiations is large. 'Infrequency', then, expresses the fact that a considerable stretch of time passes between each instantiation of an event.

2. Stump (1981: 222) cites some counterexamples to this restriction (his exs. (7) and (20)):

(i) Mary paid her friend a frequent visit.

(ii) John enjoys a frequent vacation in Palm Springs.

However, many speakers of English consider sentences like (i) and (ii) at best marginal. I will therefore consider these cases to be exceptions to the restriction in the main text.

3. In a way, (11a) is a hybrid between both approaches, since it involves unselective binding over an event argument (cf. Doetjes 1997:231f. for discussion).

4. Furthermore, on a weak quantifier analysis, both semantic structures in (11a,b) have the same truth-conditions due to intersectivity. In 3.4, I will present arguments in favour of a weak status of the quantificational element in OCs.

5. Given Kayne's (1994:23) definition of asymmetric c-command, the raised adjective can c-command into the VP because it is located in the specifier position of a specifier.

6. Matthewson (1998) assumes the DP-quantifier to be adjoined to DP rather than being located in SpecDP.

7. The approach is neutral regarding the question at which syntactic level CQF applies. Intervening material at s-structure would also block CQF at LF due to the syntactic constraints discussed in the main text below. Phonological evidence, e.g. 
from cliticization, is equally unreliable as a diagnostic for overt incorporation because articles show a tendency to cliticize on the following NP in general. Of course, if Kayne's (1994) LCA is valid, CQF will have to be located at LF because in Kayne's system head-adjunction always occurs to the left.

8. The intuititive idea behind this generalization is the following: Complex syntactic items with particular semantic properties can only be formed if these properties do not clash with intrinsic semantic properties of their parts. In (19a,b), the intrinsic quantificational or referential properties of quantifiers and deictic items, keep these elements from undergoing CQF.

9. Another possible candidate for a complex quantifier is German die meisten 'most'.

10. The QP-analysis of OCs predicts English OCs to occur in every position to which $\mathrm{QR}$ can independently apply. Since $\mathrm{QR}$ applies in (ii), giving the every-QP wide scope, the degraded status of (i) is surprising:

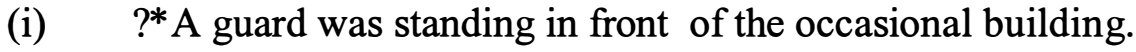

(ii) A guard was standing in front of every building.

I assume that (i) is bad because the meaning of occasional, requiring a sequencing in time, does not match the presentational simultanity of (i), expressed by the progressive. If we choose the adjective odd, which is the preferred OC-choice in non-temporal contetxs, (i) gets better:

(iii) A guard was standing in front of the odd building.

Also, (i) gets significantly better if we add a sequential context:

(iv) As we were driving down the street, a guard was standing in front of the occasional building.

11. My explanation for the absence of VP-internal OCs in German is at odds with recent minimalist assumptions that all arguments leave VP at LF for reasons of Case checking (e.g. Chomsky 1995, ch.3). If so, they should always be able to bind the VP-internal event variable at LF. I can offer no solution compatible with standard minimalist assumptions, but see e.g. Sportiche (1990) for an account that locates the Case-position of direct objects inside VP.

12. We could mend this problem and uphold the strong quantifier analysis by assuming a semantic structure like (i), which correctly predicts (28) to be true in both situations:

(i) INFREQ $<$ e $>$ [part-of(e,e*)]: $\exists<x>$ ship'(x,e) \& watch'(we, $x, e)$ $=$ 'Few events e are such that there is a ship $\mathrm{x}$ and we watch $\mathrm{x}$ at $\mathrm{e}$.'

But by doing so, we would lose the isomorphy between syntactic and semantic structure because now the NP-complement of the quantifier is not in its restriction, but in its nuclear scope.

13. The observation that '[...] if a sentence like An occasional sailor strolls by [...] is true at an interval $i$, the subintervals of $i$ at which $A$ sailor strolls by is the case must be distributed throughout $i$, and not all clumped together', led Stump (1981:229) to treat complex determiners in OCs as frequency operators, and not as unselective quantifiers over cases (cf. Lewis 1975). 
14. Perhaps we can extend this treatment of OCs to another instance of eventmodification by a DP-internal adjective, observed by Larson (1999). The synonymity of (i) and (ii) may be due to the fact that the determiner the and the adjective individual in (i) combine to form a pluractional head. This D+A-head modifies the event structure, resulting in distribution of events over students.

(i) $\quad[[[$ The individual] students $]$ [came in $]]$.

(ii) The students came in individually.

\section{References}

Bolinger, D. (1967). Adjectives in English: Attribution and Predication. Lingua $18,1-34$.

Chomsky, N. (1995). The Minimalist Program. MIT Press, Cambridge/MA.

Davidson, D. (1967). The logical form of action sentences. In N. Rescher (ed.) The Logic of Decision and Action., University of of Pittsburgh Press, Pittsburgh.

Doetjes, J. (1997). Quantifiers and Selection. On the Distribution of Quantifying expressions in French, Dutch and English. HAG, The Hague.

Fiengo, R. \& J. Higginbotham (1981). Opacity in NP. Linguistic Analysis 7, pp. 395-421.

Fintel, K. von (1994). Restrictions on Quantifier Domains. Diss., University of Massachussetts, Amherst.

Frey, W. (1993). Syntaktische Bedingungen für die semantische Interpretation. Über Bindung, implizite Argumente und Skopus, Akademie Verlag, Berlin.

Haspelmath, M. (1995). Diachronic sources of "All" and "Every". Bach, E. et al. (eds.), Quantification in Natural Languages. Kluwer, Dordrecht/Boston, pp. 363-382.

Heim, I. (1982). The Semantics of Definite and Indefinite Noun Phrases, Diss., University of Massachusetts, Amherst.

- (1990). E-type pronouns and donkey anaphora. Linguistics and Philosophy 13, pp.137-177.

Heim, I. \& A. Kratzer (1998). Semantics in Generative Grammar. Blackwell, Oxford.

de Hoop, Helen (1995). On the characterization of the weak-strong distinction. Bach, E. et al. (eds.), Quantification in Natural Languages. Kluwer, Dordrecht/Boston. pp.421-450.

Kamp, H. (1981). A theory of truth and semantic interpretation. Groenendijk, J. et al. (eds.), Truth, Interpretation and Information.Foris, Dordrecht, pp. 1-41.

Kayne, R. (1994). The Antisymmetry of Syntax. MIT Press, Cambridge/MA.

Kratzer, A. (1995). Stage-Level \& Individual-Level Predicates. Carlson, G. \& F. Pelletier (eds.), The Generic Book. University of Chicago Press, Chicago, pp. 125-175. 
Krifka, M. (1998). Scope Inversion under the Rise-Fall Contour in German. Linguistic Inquiry 29, pp. 75-109.

Larson, R. (1999). Semantics of Adjectival Modification. LOT Winterschool Class Notes, Amsterdam.

Lasersohn, P. (1995). Plurality, Conjunction and Events. Kluwer, Dordrecht/Boston.

Lewis, D. (1975). Adverbs of Quantification. Keenan, E. (ed.), Formal Semantics of Natural Language. Cambridge University Press, Cambridge, pp. 3-15.

Matthewson, L. (1998). Determiner Systems and Quantificational Strategies. Evidence from Salish. Holland Academic Graphics, The Hague.

Milsark, G. (1977). Toward an explanation of certain peculiarities of the existential construction in English. Linguistic Analysis 3. pp. 1-29.

Montague, R. (1973). The proper treatment of quantification in ordinary English. Hintikka, K.J.J. et al. (eds.), Approaches to Natural Language, Reidel, Dordrecht, pp. 221-42.

Pafel, J. (1993). Scope and Word Order. Jacobs J. et. al. (eds.), Syntax. An International Handbook of Contemporary Research,Vol. 1. de Gruyter, Berlin/New York, pp. 867-880.

Rizzi, L. (1990). Relativized Minimality. MIT Press, Cambridge/MA.

Ross, J. R. (1967). Constraints on Variables in Syntax. Diss., MIT, Cambridge/MA.

Sportiche, D. (1990). Movement, Agreement, and Case. Ms. UCLA, Los Angeles.

Stump, G. (1981). The interpretation of frequency adjectives. Linguistics and Philosophy 5, pp. 221-256.

De Swart, H. (1991). Adverbs and Quantification: A Generalized Approach. [Diss.], University of Groningen.

Sæbø, K.J. (1995). Quantifiers: Configurations and Interpretations. Hamm, F., J. Kalb, and A.v. Stechow (eds.), The Blaubeuren Papers. Proceedings of the Workshop on Recent Developments in the Theory of Natural Language Semantics, vol.2, pp. 347-378.

Travis, L. (1984). Parameters and Effects of Word Order Variation. Diss., MIT, Cambridge/MA. 